\title{
Tuta absoluta (Meyrick, 1917) (Lepidoptera: Gelechiidae) ile Mücadelede Topraktan Uygulanan Bazı Pestisitlerin Etkisi
}

\author{
Mehmet MANAVOĞLU ${ }^{1}$, Ali KAYAHAN ${ }^{*}$, İsmail KARACA ${ }^{3}$ \\ 1Isparta Uygulamalı Bilimler Üniversitesi, Tarım Bilimleri ve Teknolojileri Fakültesi, Bitki Koruma Bölümü, \\ Isparta \\ ${ }^{1}$ (ORCID: https://orcid.org/0000-0003-4272-3867) \\ 3 (ORCID: https://orcid.org/0000-0002-3671-254X) \\ 2Yozgat Bozok Üniversitesi, Ziraat Fakültesi, Bitki Koruma Bölümü, Yozgat \\ ${ }^{2}$ (ORCID: https://orcid.org/0000-0002-0975-789X)
}

(Alınış / Received: 15.08.2018, Kabul / Accepted: 15.02.2018, Online Yayınlanma / Published Online: 23.04.2019)

Anahtar Kelimeler Chlorantraniliprole, Domates güvesi, Flubendiamide, Thiometoxam
Özet: Dünyada üretilen sebzeler içerisinde büyük paya sahip olan sebze domatestir. Ülkemizde ve dünyada yoğun şekilde üretimi yapılan domates bitkilerini tehdit eden çok sayıda hastalık ve zararlı yer almaktadır. Bu zararlılardan birisi olan Tuta absoluta (Meyrick, 1917) (Lepidoptera: Gelechiidae), domates bitkisi yaprağının iki epidermisi arasında, sürgünlerde ve meyvede beslenerek ekonomik kayıplara neden olmaktadır. Bu çalışmada, bazı pestisitlerin Akdeniz Bölgesi'nde seralarda ve açık alanlarda ekonomik zarara neden olan Domates güvesi (T. absoluta) ile kimyasal mücadelede klasik uygulamaların dışında topraktan uygulama denemeleri yürütülmüştür. Uygulanan pestisitlerin özellikle böceğin davranışı, beslenmesi, yaşamları üzerindeki etkilerinin yanında uygulanan alanda zararlıya karşı kültür bitkisinin koruma süresi araştırılmıştır. Bu çalışmada değişik etkili maddelere sahip ticari ilaçlar (İlaç1, İlaç2 ve İlaç3) kullanılmıştır. İlaçlar arasında etkililik açısından fark olup olmadığının kıyaslaması için SPSS programı kullanılmış, ortaya çıkabilecek istatistiki farklılıklar ise Tukey çoklu karşılaştırma testi ile belirlenmiştir. Denemelerden elde edilen sonuçlar karşılaştırıldığında İlaç1 ve İlaç2 isimli kimyasalların topraktan uygulandığında $T$. absoluta'ya etkili olduğu görülmüştür.

\section{Effects of Some Pesticides Against Tuta absoluta (Meyrick, 1917) (Lepidoptera: Gelechiidae) by Soil Application}

\section{Keywords}

Chlorantraniliprole,

Tomato leaf miner,

Flubendiamide,

Thiometoxam

\begin{abstract}
Tomato has a large share in the vegetables produced on the world. So many diseases and insects are thereaten the tomato in Turkey and World. One of these insect Tuta absoluta (Meyrick, 1917) (Lepidoptera: Gelechiidae), is making economical loses by feeding itselfs between two epidermis of leaf, shoots and fruits of tomatoes. In this study, in case of classical thereatments in chemical control againts Tomato Leaf Miner (T. absoluta), in the Mediterranean area, soil application trials has setted. Checked the effect of pesticides against insect behaivor, feeding and lives and also protection time for cultivation plant. In this research different active ingredient pesticides were used. (Pesticide1, Pesticide2 ve Pesticide3). To check the differences between the pesticides SPSS program were used and for the different statistical results Tukey test has used. When you check out the results Pesticide1 and Pesticide2 were effective against T. absoluta by drip irrigation.
\end{abstract}

\section{Giriş}

Dünyada besin olarak kullanılan ve önemli derecede üretimi olan sebzelerin yetiştiriciliği 19. yüzyılda başlamıștır [1]. FAO verilerine göre dünyada 57.2 milyon hektar alanda 1.1 milyar ton yaş sebze üretimi yapılmış ve yıllar geçtikçe bu üretimin arttığı görülmektedir. Dünyada ve ülkemizde önemli 
derecede üretim potansiyeline sahip olan domates patatesten sonra en önemli sebze konumundadır. İlk defa Meksikalılar tarafından kültüre alınan domates daha sonra Amerika, Avrupa ve diğer ülkelere yayılmiştır [2]. Türkiye'nin hemen hemen tüm bölgelerinde yetiştiriciliği yapılan domates, gerek taze tüketim gerekse ketçap, salça ve domates suyu şeklinde de değerlendirilmektedir. Son yillarda yapılan üretimlere bakıldığında, dünyada yaklaşık 4,8 milyon hektar alanda yaklaşı 177 milyon ton domates üretimi yapılmaktadır. Ülkemiz ise yaklaşık 13 milyon ton üretim ile Çin, ABD ve Hindistan'dan sonra 4. sırada gelmektedir $[3,4]$. Ülkemizde açık ve örtü altına alınmış alanlarda yetiştiriciliği yapılan domatesin en fazla üretimi Akdeniz Bölgesi'nde (3.7 milyon ton), ikinci Ege Bölgesi'nde (1.3 milyon ton), üçüncü Karadeniz Bölgesi'nde (984 bin ton), dördüncü olarak da Marmara Bölgesi'nde (912 bin ton) yapılmaktadır [5].

Dünya geneline bakıldığında sebze üretimini ekonomik anlamda olumsuz etkileyen çok sayıda hastalık ve zararlı bulunmaktadır. Çalışmamızın da konusu olan Tuta absoluta (Meyrick, 1917) (Lepidoptera: Gelechiidae) önemli bir domates zararlısıdır [6]. Anavatanı Güney Amerika olan ve dünyada ilk kez 1917 yılında Peru'da tespit edilen bu zararlı, daha sonra 1964 yllında Arjantin'de görülmüştür. Ülkemizde ise 2009 yllında İzmir'in Urla ilçesinde tespit edilmiştir [7]. Domates bitkilerinin yapraklarının iki epidermisi arasında, sürgünlerde ve meyvede beslenerek büyük zarar yapan T. absoluta, üretim yapılan alanlara kısa sürede yayılmaktadır $[1,8,9,10,11,12,13,14,15,16,17$, 18, 19]. T. absoluta'nın domatesten bașka konukçuları da vardır. Patlıcan, patates, tütün, yabani tütün, fasulye, kaz üzümü, kurt üzümü, it üzümü ve tarla sarmaşığı bunlardan bazılarıdır [14, 16, 20, 21].

Domates bitkisinin kök hariç tüm organlarında beslenebilen bu zararlı, \%100'e varan oranda ürün kaybına neden olabilmektedir. Çok kısa sürede uzun mesafelere yaylabilen T. absoluta'nın, son yıllarda domateste meyve kalitesini bozarak verim kayıplarına ve pazar değerinin düşmesine neden olduğu görülmüștür [9, 22].

Son yıllarda yapılan çalışmalara bakıldı̆̆ında insektisitlerin yapraktan uygulanması, Güney Amerika'da ekonomik yönden zarara neden olan lepidopterlerle mücadelede önemlidir. Ancak çok sayıda bitkinin bir arada üretildiği alanlarda zararlı organizmalara karşı yapraktan insektisit uygulamaları (özellikle klorlu hidrokarbonlar, organofosfatlar, karbamatlar ve pretroidler) zararlılar üzerinde direnç gelişimine yol açmakta ve onlarla mücadelede olumsuz sonuçlar doğurmaktadır $[23,24,25,26,27]$. Diamide grubu insektisitler 2008'de piyasaya girmiştir [28]. Bu grubun bir etki mekanizması vardır ve ryanodine reseptör modülatör olarak sınıflandırılmıştır [29]. Bu insektisit grubunda iki temsilci yer almaktadır. Bunlar bir antranilik diamide olan Clorantraniliprole ve bir pthalic asit diamide olan Flubendiamide'dir [30].

Chlorantraniliprole ksilemlerde aşağıdan yukarı doğru taşınan bir insektisit grubudur [31]. Bunlar genellikle brassica ve diğer sebzelerin olduğu karıșık üretimlerde tohum ya da topraktan sulama yoluyla uygulanmaktadır [31, 32, 33, 34, 35, 36]. Yapılan bu uygulamalarla insektisitler köklerle alınır ve lepidopterlerin ve yapraklar üzerinde zararlı olan diğer organizmaların kontrolünde etkilidir [31, 36]. $\mathrm{Bu}$ etkili maddenin aksine Flubendiamide sadece yapraktan uygulamalar için sınıflandırılmıştır ve sistemik bir kimyasal olarak bilinmemektedir. Ayrıca Chlorantraniliprole ile benzer olarak diğer insektisitlerle karşılaștırıldığında daha yüksek kalıntı etkinliğine sahiptir [37].

Bu çalışmada, bazı pestisitlerin Akdeniz Bölgesi'nde seralarda ve açık alanlarda ekonomik zarara neden olan Domates Güvesi (Tuta absoluta Meyrick (Lepidoptera: Gelechiidae))'ne karşı klasik uygulamaların dışında topraktan uygulama denemeleri yürütülmüştür. Uygulanan pestisitlerin özellikle böceğin davranışı, beslenmesi, yaşamları üzerindeki etkilerinin yanında uygulanan alanda zararlıya karşı kültür bitkisinin koruma süresi araştırılmıştır. Yapılan bu çalışma ile özellikle seraların yoğun olduğu bölgelerde üreticilerin en büyük problemlerinden olan domates güvesi için daha uzun süre etkili mücadele yönteminin detayları ve sonuçları ile bu zararlıyla mücadelede yeni bir aşama kazanılmaya çalışılmıştır.

\section{Materyal ve Metot}

\subsection{Materyal}

Çalışmanın ana materyalini domates (Solanum lycopersicum L.) bitkisi, domates bitkisinin ana zararlısı olan Domates güvesi, T. absoluta ve bu zararlıya karşı denemesi yapılmış üç farklı pestisit (Tablo 1) oluşturmuştur. Bunlara ek olarak domates fidelerinin içerisine dikilmiş olduğu 2 litrelik plastik saksılar, 10x30x40 boyutlarında plastik küvetler, sayımların yapılması için Leica® EZ4 marka stereomikroskop kullanılmıştır.

Tablo 1. Denemelerde kullanılmıș olan bitki koruma ürünleri ve özellikleri

\begin{tabular}{|c|c|c|c|c|}
\hline Firma & $\begin{array}{l}\text { Ticari } \\
\text { İsim }\end{array}$ & Etkili Madde & Doz & $\begin{array}{l}\text { Uyg. } \\
\text { șekli }\end{array}$ \\
\hline $\begin{array}{l}\text { Firma } \\
1\end{array}$ & İlaç1 & Chlorantraniliprole & $\begin{array}{l}10 \mathrm{~g} / 100 \mathrm{lt} \\
\mathrm{su}\end{array}$ & Toprak \\
\hline $\begin{array}{l}\text { Firma } \\
1\end{array}$ & İlaç1 & Chlorantraniliprole & $\begin{array}{l}10 \mathrm{~g} / 100 \mathrm{lt} \\
\mathrm{su}\end{array}$ & Üst \\
\hline $\begin{array}{l}\text { Firma } \\
2\end{array}$ & İlaç2 & $\begin{array}{l}\text { Chlorantraniliprole } \\
+ \\
\text { Thiometoxam }\end{array}$ & $80 \mathrm{ml} / \mathrm{da}$ & Toprak \\
\hline $\begin{array}{l}\text { Firma } \\
3\end{array}$ & İlaç3 & Flubendiamide & $\begin{array}{l}30 \\
\mathrm{ml} / 100 \mathrm{lt} \\
\mathrm{su}\end{array}$ & Toprak \\
\hline
\end{tabular}




\subsection{Metot}

Bitki üretimleri, zararlı böceğin üretimi ve denemelerin tamamı Süleyman Demirel Üniversitesi Ziraat Fakültesi Bitki Koruma Bölümü Biyolojik Mücadele Araştırma ve Uygulama Laboratuvarında bulunan, $25 \pm 1^{\circ} \mathrm{C}$ sicaklık, \%65 \pm 5 nisbi nem ve $16: 8$ saat ışıklandırma (Aydınlık:Karanlık) koşullarına sahip iklim odalarında gerçekleştirilmiştir (Şekil 1).

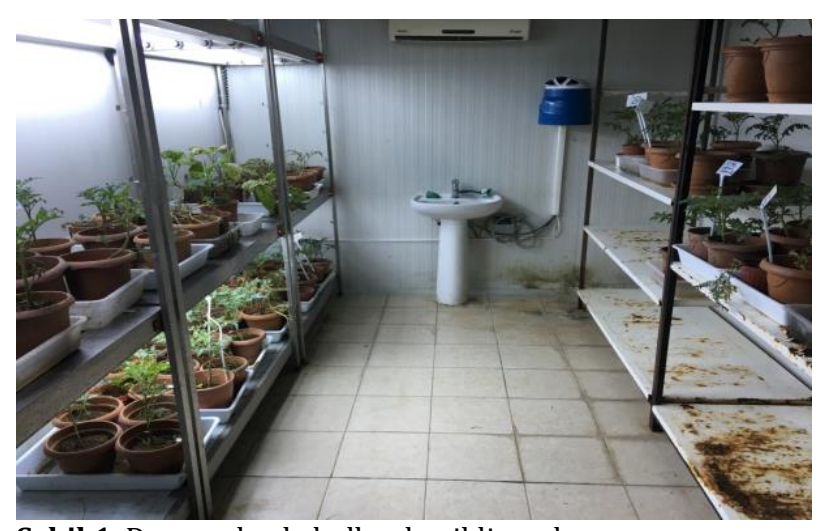

Şekil 1. Denemelerde kullanılan iklim odası

\subsubsection{Bitki üretimi}

Zararlını konukçusu olarak kullanılan domates bitkisi çalışma için iki şekilde temin edilmiştir. İlk olarak domates tohumları laboratuvardaki iklim odalarında viyollere ekilmiş ve şaşırtma için uygun döneme geldiklerinde içerisinde 1:1 oranında steril toprak ve torf karışımı bulunan saksılara dikilmiştir. İkinci olarak da ticari üretim yapan firmalardan temin edilen fideler yine aynı yöntem uygulanarak saksılara aktarılmıştır. Saksılara aktarılan fidelerin gerekli bakımları ve sulama işlemleri iki günde bir gerçekleştirilmiştir. Çalışma süresince kullanılan kimyasallar dışında herhangi bir kimyasal uygulaması yapılmamıștır. Saksılara aktarılan bitkiler 8 yapraklı döneme geldiklerinde denemeler gerçekleștirilmiştir.

\subsubsection{Zararlının (Tuta absoluta) üretimi}

T. absoluta'nın larva ve ergin bireyleri, Antalya'daki domates üretimi yapılan seralardan 2014 yılı sezonunda toplanmış ve plastik kaplar içerisinde Süleyman Demirel Üniversitesi, Ziraat Fakültesi, Bitki Koruma Bölümü, Biyolojik Mücadele Araștırma ve Uygulama Merkezi'ne getirilmiş ve temiz domates bitkileri üzerine bulaştırılarak üretimi sağlanmıştır. Yapılan denemelerde kullanılan zararlılar buradaki kitle üretiminden sağlanmıştır.

\subsubsection{Denemelerin Kurulması}

Denemelerde kullanılan domates bitkileri 8 yapraklı döneme geldiklerinde Tablo 1'de gösterilen ilaçların uygulaması iki farklı şekilde yapılmıştır. İlk yöntemde 3 farklı kimyasal (İlaç1, İlaç2 ve İlaç3) topraktan uygulanırken; İlaç1 isimli kimyasalın topraktan denenmesinin yanında üstten de püskürtme şeklinde uygulanması yapılmıştır.

İlaç uygulaması yapılan domates bitkileri, uygulanan ilacı bünyelerine alması için iki gün süre ile içerisinde herhangi zararlı bulundurmayan $25 \pm 1{ }^{\circ} \mathrm{C}$ sicaklık, $\% 65 \pm 5$ nem ve 16:8 (Aydınlık:karanlık) saat ıșıklandırma koşullarına sahip iklim odalarında bekletilmiştir.

İki gün sonra ilaçlı domates bitkileri Tuta absoluta'nın olduğu iklim odasına alınmıștır. Her bir uygulamada 10'ar adet domates bitkisi kullanılmış ve her sayımda $15^{\prime}$ er adet yaprak alınmıştır. Uygulamaların yapıldığı domates bitkilerinin yanına zararlı ile bulaşık domates bitkileri konulmuş ve domates güvesinin ilaçlı bitkilere tesadüfi bulaşması sağlanmıștır. Bu işlem her bir uygulama için aynı iklim odası içinde fakat ayrı ayrı raflarda gerçekleştirilmiştir (Şekil 2).

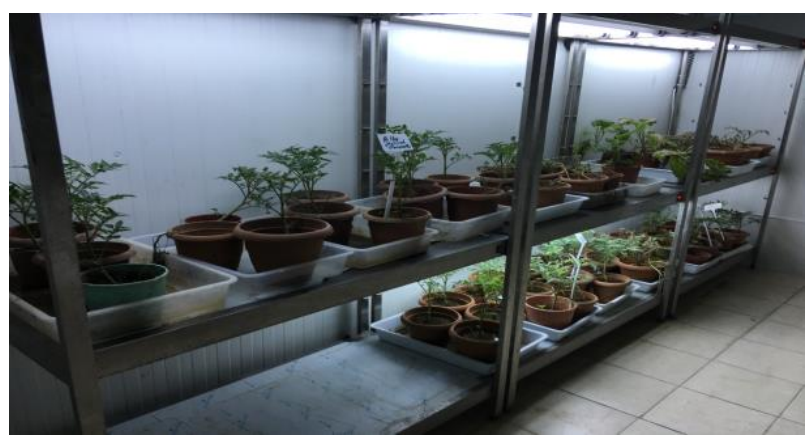

Şekil 2. Denemelerin gerçekleștirildiği oda içerisindeki raflar ve uygulamalar

Domates güvesi ile bulaşık iklim odasında tutulan (30 gün boyunca) ve pestisit uygulaması yapılan bitkiler 10 'ar gün aralıklarla örneklenmiştir. Bu amaçla, her bir uygulamadan ikişer saksı sayım için laboratuvara taşınmıştır. Bitkiler yaprağın gövdeye birleştiği yerden kesilerek, stereo mikroskop altında zararlının canlı-öl- larvaları, yumurtaları ve galerileri sayılmıştır (15 yaprak üzerinde). Sayımlar 10., 20. ve 30. gün olmak üzere $3 \mathrm{kez}$ yapılmıștır. Sayımlar sonucunda, T. absoluta ile mücadelede uygulanan ilaçların etki süreleri belirlenmiştir.

\subsubsection{Denemelerin değerlendirilmesi}

İlaçlar arasında etkililik açısından fark olup olmadığının kıyaslaması için SPSS programı kullanılmış, ortaya çıkabilecek istatistiki farklılıklar ise Tukey çoklu karşlaştırma testi ile belirlenmiştir. Analizlerin yapılmasında SPSS (Ver. 17), MS Excel, Curve Expert (ver. 1.6), JMP (Ver. 9) programlarından yararlanılmıștır.

\section{Bulgular}

$\mathrm{Bu}$ çalışmada elde edilen verilere göre 10 . günde yapılan sayım sonuçlarına bakılarak T. absoluta'nın farklı uygulamalardaki domates bitkilerinin 
yaprakları üzerine yumurta bırakma miktarlarının uygulamalara göre değişiklik gösterdiği saptanmıștır. Elde edilen verilere göre İlaç3 ile İlaç2 uygulamalarında elde edilen yumurta sayıları ve İlaç1 (Topraktan) ile Kontrol uygulamalarinda elde edilen yumurta sayları kendi aralarında benzer iken ( $>>0.05)$; bu iki grubun arasındaki farkın istatistiksel olarak önemli olduğu görülmüştür $(\mathrm{p}<0.05)$. Yapılan hesaplamalara göre en fazla bırakılan yumurtanın İlaç1 (Topraktan) ve Kontrol uygulamalarında olduğu saptanmıştır. Aynı sayım sonucunda elde edilen verilere göre farklı uygulamalarda İlaç2 uygulamasında canlı larvalara rastlanmazken; en yüksek canlı larva kontrol uygulanmasında görülmüştür. Bunlara ek olarak İlaç1 (Topraktan), İlaç2 uygulamalarında elde edilen canlı larva sayıları kontrole göre farklı bulunmuştur $(\mathrm{p}<0.05)$. Ayrıca en yüksek ölü larva sayısının İlaç1 (Topraktan) uygulamasında olduğu görülürken; İlaç2 uygulamasında ölü larvaya rastlanmamıștır. Buna ek olarak İlaç2 uygulaması ile kontrol kendi aralarında benzerlik gösterirken ( $\mathrm{p}>0.05)$; bu iki uygulamanın İlaç1 (Topraktan) uygulamasından farklı olduğu görülmüştür $(\mathrm{p}<0.05)$. Galeri sayıları incelendiğinde, İlaç1 (Topraktan) ve İlaç2 uygulamalarında galeriye rastlanmazken; en yüksek galeri sayısı İlaç3 uygulamasında gözlenmiştir. Ayrıca İlaç3 uygulamasında elde edilen galeri sayıları ile kontrol parseli dâhil olmak üzere diğer uygulamalardaki galeri sayıları arasındaki farkın istatistiksel olarak önemli olduğu görülmektedir ( $\mathrm{p}<0.05)$ (Tablo 2).

Tablo 2. Denemenin 10. gündeki bitki sayım sonuçları

\begin{tabular}{|c|c|c|c|c|c|}
\hline & $\mathbf{N}$ & Yumurta & Canlı & ölü & Galeri \\
\hline $\begin{array}{l}\text { İlaç1 } \\
\text { (Üst) }\end{array}$ & 15 & $\begin{array}{l}2.60 \pm \\
0.584 \mathrm{ab}\end{array}$ & $\begin{array}{l}1.20 \pm \\
0.416 \mathrm{ab}\end{array}$ & $\begin{array}{l}0.93 \pm \\
0.358 \mathrm{ab}\end{array}$ & $\begin{array}{l}3.60 \pm \\
0.786 \mathrm{~b}\end{array}$ \\
\hline $\begin{array}{l}\text { İlaç1 } \\
\text { (Toprak) }\end{array}$ & 15 & $\begin{array}{l}4.40 \pm \\
1.370 \mathrm{a}\end{array}$ & $\begin{array}{l}0.07 \pm \\
0.067 \text { bc }\end{array}$ & $\begin{array}{l}1.87 \pm \\
0.631 \text { a }\end{array}$ & $\begin{array}{l}0.00 \pm \\
0.000 \mathrm{c}\end{array}$ \\
\hline $\begin{array}{l}\text { İlaç2 } \\
\text { (Toprak) }\end{array}$ & 15 & $\begin{array}{l}0.67 \pm \\
0.667 \mathrm{~b}\end{array}$ & $\begin{array}{l}0.00 \pm \\
0.000 \mathrm{c}\end{array}$ & $\begin{array}{l}0.00 \pm \\
0.000 \mathrm{~b}\end{array}$ & $\begin{array}{l}0.00 \pm \\
0.000 \mathrm{c}\end{array}$ \\
\hline $\begin{array}{l}\text { İlaç3 } \\
\text { (Toprak) }\end{array}$ & 15 & $\begin{array}{l}0.60 \pm \\
0.254 \mathrm{~b}\end{array}$ & $\begin{array}{l}1.13 \pm \\
0.256 \text { abc }\end{array}$ & $\begin{array}{l}0.73 \pm \\
0.182 \mathrm{ab}\end{array}$ & $\begin{array}{l}5.93 \pm \\
0.643 \mathrm{a}\end{array}$ \\
\hline Kontrol & 15 & $\begin{array}{l}4.27 \pm \\
0.679 \mathrm{a}\end{array}$ & $\begin{array}{l}1.93 \pm \\
0.463 \mathrm{a}\end{array}$ & $\begin{array}{l}0.67 \pm \\
0.667 \mathrm{~b}\end{array}$ & $\begin{array}{l}2.60 \pm \\
0.576 \mathrm{~b}\end{array}$ \\
\hline
\end{tabular}

(Aynı sütundaki farklı harfler istatistiki açıdan bir farkın olduğunu göstermektedir, $\mathrm{p}<0.05 ; \mathrm{DF}_{\text {yumurta: }} 4, \mathrm{~F}_{\text {yumurta: }} 1.79, \mathrm{P}_{\text {yumurta: }}$ 0.140;

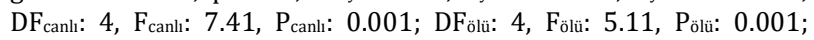
$\mathrm{DF}_{\text {galeri: }} 4, \mathrm{~F}_{\text {galeri: }}$ 23.38, $\mathrm{P}_{\text {galeri: }}$ 0.001; N: Yaprak sayısı)

Elde edilen verilere göre 20. günde yapılan sayım sonuçlarına bakılarak T. absoluta'nın farklı uygulamalardaki domates bitkilerinin yaprakları üzerine yumurta bırakma miktarlarının uygulamalara göre değişiklik gösterdiği gözlenmiștir. En fazla yumurta İlaç1 (Topraktan) uygulanmasında görülürken; bu uygulamanın istatistiksel olarak diğer uygulamalardan farklı olduğu tespit edilmiştir $(\mathrm{p}<0.05)$. Aynı sayımdan elde edilen verilere göre farklı uygulamalarda İlaç1 (Topraktan) uygulamasında canlı larvalara rastlanmazken; en yüksek canlı larva kontrol uygulanmasında görülmüştür. Bunlara ek olarak Kontrol uygulamasında elde edilen verilerin diğer uygulamalara göre aralarında istatistiksel bir farkın olduğu tespit edilmiştir $(\mathrm{p}<0.05)$. Ayrıca en yüksek ölü larva sayısının İlaç1 (Topraktan) uygulamasında olduğu görülürken; en düşük ölü larva sayısının kontrol uygulamasında saptanmıștır. Bunun yanında İlaç1 (Topraktan) uygulamasının diğer uygulamalardan istatistiksel olarak farklı olduğu görülmüştür $(p<0.05)$. Buna ek olarak en yüksek galeri sayısına kontrol uygulamasında rastlanırken; en düşük galeri sayısının ise İlaç1 (Topraktan) ve İlaç2 uygulamalarında olduğu görülmüștür. Bu iki uygulamada elde edilen verilerin istatistiksel olarak diğer uygulamalardan farklı olduğu saptanmıştır $(\mathrm{p}<0.05)$ (Tablo 3).

Tablo 3. Denemenin 20. gündeki bitki sayım sonuçları

\begin{tabular}{|c|c|c|c|c|c|}
\hline & $\mathbf{N}$ & Yumurta & Canlı & Ölü & Galeri \\
\hline $\begin{array}{l}\text { İlaç1 } \\
\text { (Üst) }\end{array}$ & 15 & $\begin{array}{l}1.60 \pm \\
0.600 \mathrm{~b}\end{array}$ & $\begin{array}{l}1.93 \pm \\
0.539 \text { b }\end{array}$ & $\begin{array}{l}5.00 \pm \\
0.822 \text { bc }\end{array}$ & $\begin{array}{l}12.2 \pm \\
1.230 \mathrm{~b}\end{array}$ \\
\hline $\begin{array}{l}\text { İlaç1 } \\
\text { (Toprak) }\end{array}$ & 15 & $\begin{array}{l}3.87 \pm \\
0.716 \text { a }\end{array}$ & $\begin{array}{l}0.00 \pm \\
0.000 \mathrm{c}\end{array}$ & $\begin{array}{l}10.47 \pm \\
1.18 \mathrm{a}\end{array}$ & $\begin{array}{l}1.27 \pm \\
0.345 \text { c }\end{array}$ \\
\hline $\begin{array}{l}\text { İlaç2 } \\
\text { (Toprak) }\end{array}$ & 15 & $\begin{array}{l}1.33 \pm \\
0.523 \text { b }\end{array}$ & $\begin{array}{l}0.13 \pm \\
0.133 \text { bc }\end{array}$ & $\begin{array}{l}4.07 \pm \\
0.651 \text { bc }\end{array}$ & $\begin{array}{l}2.73 \pm \\
0.358 \mathrm{c}\end{array}$ \\
\hline $\begin{array}{l}\text { İlaç3 } \\
\text { (Toprak) }\end{array}$ & 15 & $\begin{array}{l}1.33 \pm \\
0.347 \text { b }\end{array}$ & $\begin{array}{l}0.40 \pm \\
0.163 \mathrm{bc}\end{array}$ & $\begin{array}{l}5.80 \pm \\
0.927 \text { b }\end{array}$ & $\begin{array}{l}9.40 \pm \\
1.080 \mathrm{~b}\end{array}$ \\
\hline Kontrol & 15 & $\begin{array}{l}0.80 \pm \\
0.341 \mathrm{~b}\end{array}$ & $\begin{array}{l}8.73 \pm \\
0.913 \text { a }\end{array}$ & $\begin{array}{l}2.20 \pm \\
0.393 \mathrm{c}\end{array}$ & $\begin{array}{l}17.3 \pm \\
1.240 \mathrm{a}\end{array}$ \\
\hline
\end{tabular}

(Aynı sütundaki farklı harfler istatistiki açıdan bir farkın olduğunu göstermektedir, $\mathrm{p}<0.05$; $\mathrm{DF}_{\text {yumurta: }} 4 \mathrm{~F}_{\text {yumurta: }} 5.19, \mathrm{P}_{\text {yumurta: }}$ 0.001; $\mathrm{DF}_{\text {canll }}: 4, \mathrm{~F}_{\text {canhl: }}: 58.99, \mathrm{P}_{\text {canll: }}: 0.001 ; \mathrm{DF}_{\text {ölü: }}$ 4, $\mathrm{F}_{\text {ölü: }}$ 13.55, Pölü: 0.001; $\mathrm{DF}_{\text {galeri: }} 4, \mathrm{~F}_{\text {galeri: }}$ 49.87, $\mathrm{Pgaleri}$ : 0.001; N: Yaprak sayısı)

Bu çalışmada son sayım olan 30 . gün sonundaki elde edilen verilere göre $T$. absoluta'nın farklı uygulamalardaki domates bitkilerinin yaprakları üzerine yumurta bırakma miktarlarının uygulamalara göre çok az değişiklik gösterdiği saptanırken; aralarında istatistiksel bir farkın olmadığ görülmüștür ( $p>0.05)$. Ayrıca İlaç1 (Topraktan) ve İlaç2 uygulamalarında canlı larvalara rastlanmazken; en yüksek canlı larvaya kontrol uygulanmasında rastlanmıștır. Bunun yanında ilk dört uygulama kendi aralarında istatistiksel benzerlik gösterirken ( $>$ >0.05); bu uygulamaların kontrole göre farklı olduğu belirlenmiştir $(\mathrm{p}<0.05)$. Elde edilen verilere göre en fazla ölü larvanın olduğu uygulama İlaç2 uygulaması iken; en düșük ölü larva sayısının İlaç1 (Üstten) uygulamasında olduğu saptanmıştır. İlaç2 uygulamasında elde edilen verilerin istatistiksel olarak diğer uygulamalardan farklı olduğu görülmüştür $(\mathrm{p}<0.05)$. Elde edilen verilere bakarak, en yüksek galeri sayısına kontrol ve İlaç1 (Üstten) uygulamalarında rastlanırken; en düşük galeri sayısının ise İlaç1 (Topraktan) ve İlaç2 uygulamalarında olduğu görülmüştür. $\mathrm{Bu}$ iki uygulamada elde edilen verilerin istatistiksel olarak diğer uygulamalardan farklı olduğu saptanmıștır $(\mathrm{p}<0.05)$ (Tablo 4). 
Tablo 4. Denemenin 30. gündeki bitki sayım sonuçları

\begin{tabular}{|c|c|c|c|c|c|}
\hline & $\mathbf{N}$ & Yumurta & Canlı & ölü & Galeri \\
\hline $\begin{array}{l}\text { İlaç1 } \\
\text { (Üst) }\end{array}$ & 15 & $\begin{array}{l}1.13 \pm \\
0.467 \text { a }\end{array}$ & $\begin{array}{l}1.60 \pm \\
0.388 \mathrm{~b}\end{array}$ & $\begin{array}{l}1.20 \pm \\
0.296 \mathrm{c}\end{array}$ & $\begin{array}{l}13.33 \pm \\
1.71 \mathrm{a}\end{array}$ \\
\hline $\begin{array}{l}\text { İlaç1 } \\
\text { (Toprak) }\end{array}$ & 15 & $\begin{array}{l}1.53 \pm \\
0.350 \mathrm{a}\end{array}$ & $\begin{array}{l}0.00 \pm \\
0.000 \mathrm{~b}\end{array}$ & $\begin{array}{l}3.60 \pm \\
0.646 \text { bc }\end{array}$ & $\begin{array}{l}2.73 \pm \\
0.771 \mathrm{c}\end{array}$ \\
\hline $\begin{array}{l}\text { İlaç2 } \\
\text { (Toprak) }\end{array}$ & 15 & $\begin{array}{l}0.47 \pm \\
0.336 \text { a }\end{array}$ & $\begin{array}{l}0.00 \pm \\
0.000 \mathrm{~b}\end{array}$ & $\begin{array}{l}10.33 \pm \\
1.38 \mathrm{a}\end{array}$ & $\begin{array}{l}1.53 \pm \\
0.336 \mathrm{c}\end{array}$ \\
\hline $\begin{array}{l}\text { İlaç3 } \\
\text { (Toprak) }\end{array}$ & 15 & $\begin{array}{l}1.33 \pm \\
0.374 \mathrm{a}\end{array}$ & $\begin{array}{l}0.27 \pm \\
0.153 \mathrm{~b}\end{array}$ & $\begin{array}{l}4.73 \pm \\
0.808 \mathrm{~b}\end{array}$ & $\begin{array}{l}8.53 \pm \\
0.506 \mathrm{~b}\end{array}$ \\
\hline Kontrol & 15 & $\begin{array}{l}1.80 \pm \\
0.341 \mathrm{a}\end{array}$ & $\begin{array}{l}11.93 \pm \\
0.81 \mathrm{a}\end{array}$ & $\begin{array}{l}1.87 \pm \\
0.363 \text { bc }\end{array}$ & $\begin{array}{l}17.47 \pm \\
1.29 \mathrm{a}\end{array}$ \\
\hline
\end{tabular}

(Aynı sütundaki farklı harfler istatistiki açıdan bir farkın olduğunu göstermektedir, $\mathrm{p}<0.05$; DF yumurta: 4, Fyumurta: 5.19, Pyumurta: 0.001; $\mathrm{DF}_{\text {canll: }} 4, \mathrm{~F}_{\text {canll: }}$ 159.99, $\mathrm{P}_{\text {canll: }}$ 0.001; DFölü: 4, Fölü: 20.61, Pölü: 0.001; $\mathrm{DF}_{\text {galeri: 4, }}$ galeri: 41.67, Pgaleri: 0.001; N: Yaprak sayısı)

Elde edilen verilere değerlendirildiğinde yapılan tüm sayımların analizine göre T. absoluta'nın farklı uygulamalardaki domates bitkilerinin yaprakları üzerine yumurta bırakma miktarlarının uygulamalara göre değişiklik gösterdiği belirlenmiştir. T. absoluta en fazla yumurtayı İlaç1 (Topraktan) uygulamasındaki domates bitkileri üzerine bırakırken; en az yumurtayı İlaç2 uygulamasındaki domates bitkileri üzerine bırakmıștır. Yapılan analizlere göre en fazla yumurtayı İlaç1 (Topraktan) uygulamasındaki domates bitkileri üzerine bırakmasına rağmen; uygulama sonundaki analizlere göre en az galeri, en az canlı larva ve en fazla ölüm bu uygulamada görülmüştür. Benzer şekilde İlaç2 uygulamasında bırakılan yumurta sayısı İlaç1 (Topraktan) uygulamasına göre farklı olmasına rağmen $(\mathrm{p}<0.05)$; canlı, ölü larva sayıları ve galeri sayıları arasında istatistiksel bir benzerlik olduğu görülmektedir ( $p>0.05)$. Bunun yanında elde edilen verilere göre olması beklendiği gibi en yüksek canlı larva ve galeri sayısı, en düşük ölü larva sayısı kontrol uygulamasında saptanmıștır. Burada elde edilen verilerin de diğer uygulamalardan istatistiksel olarak farklı olduğu görülmektedir ( $\mathrm{p}<0.05)$ (Tablo 5).

Tablo 5. Yapılan sayımların tümünden elde edilen sonuçlar

\begin{tabular}{|c|c|c|c|c|c|}
\hline & $\mathbf{N}$ & Yumurta & Canlı & ölü & Galeri \\
\hline $\begin{array}{l}\text { İlaç3 } \\
\text { (Toprak) }\end{array}$ & 45 & $\begin{array}{l}1.09 \pm \\
0.193 \text { bc }\end{array}$ & $\begin{array}{l}0.60 \pm \\
0.125 \text { bc }\end{array}$ & $\begin{array}{l}3.76 \pm \\
0.521 \text { ab }\end{array}$ & $\begin{array}{l}7.96 \pm \\
0.493 \mathrm{~b}\end{array}$ \\
\hline $\begin{array}{l}\text { İalç1 } \\
\text { (Toprak) }\end{array}$ & 45 & $\begin{array}{l}3.27 \pm \\
0.549 \text { a }\end{array}$ & $\begin{array}{l}0.02 \pm \\
0.022 \mathrm{c}\end{array}$ & $\begin{array}{l}5.31 \pm \\
0.740 \text { a }\end{array}$ & $\begin{array}{l}1.33 \pm \\
0.323 \mathrm{c}\end{array}$ \\
\hline $\begin{array}{l}\text { İlaç2 } \\
\text { (Toprak) }\end{array}$ & 45 & $\begin{array}{l}0.82 \pm \\
0.230 \mathrm{c}\end{array}$ & $\begin{array}{l}0.04 \pm \\
0.044 \mathrm{c}\end{array}$ & $\begin{array}{l}4.80 \pm \\
0.811 \mathrm{a}\end{array}$ & $\begin{array}{l}1.42 \pm \\
0.232 \mathrm{c}\end{array}$ \\
\hline $\begin{array}{l}\text { İlaç1 } \\
\text { (Üst) }\end{array}$ & 45 & $\begin{array}{l}1.78 \pm \\
0.325 \text { bc }\end{array}$ & $\begin{array}{l}1.58 \pm \\
0.259 \mathrm{~b}\end{array}$ & $\begin{array}{l}2.38 \pm \\
0.416 \text { bc }\end{array}$ & $\begin{array}{l}9.71 \pm \\
0.983 \\
\text { ab }\end{array}$ \\
\hline Kontrol & 45 & $\begin{array}{l}2.29 \pm \\
0.349 \text { ab }\end{array}$ & $\begin{array}{l}7.53 \pm \\
0.759 \mathrm{a}\end{array}$ & $\begin{array}{l}1.38 \pm \\
0.225 \mathrm{c}\end{array}$ & $\begin{array}{l}12.47 \pm \\
1.22 \mathrm{a}\end{array}$ \\
\hline
\end{tabular}

$\overline{\text { (Aynı sütundaki farklı harfler istatistiki açıdan bir farkın olduğunu }}$

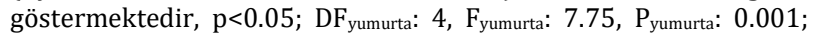
$\mathrm{DF}_{\text {canll: }}$ 4, $\mathrm{F}_{\text {canll: }}$ 76.49, $\mathrm{P}_{\text {canll: }}$ 0.001; DFölü: 4, Fölü: 7.94, Pölü: 0.001; $\mathrm{DF}_{\text {galeri: }} 4, \mathrm{~F}_{\text {galeri: }}$ 44.08, $\mathrm{P}_{\text {galeri: }}$ 0.001; $\mathrm{N}$ : Yaprak sayısI)

\section{Tartışma ve Sonuç}

Yapılan bir çalışmada araştırıcılar Tuta absoluta'ya karşı savaşımda önerilen Chlorantranilipirole (CTPR) + Abamectin ile bazı çevreye zararı olmayan ilaçların (Bacillus thuringiensis var. kurstaki, Thiodicarb) etkilerini püskürtme yöntemiyle belirlemeye çalışmışlardır. Kurdukları denemelerden ilkini bakanlık standart yöntemine göre hazırlarlarken; ikincisinde uygulamadan 15 gün sonraki bulaşık yaprak ve meyve oranını belirlemişlerdir. Elde ettikleri verilere göre denemelerin ilk kısmında bulaşıklık oranını $B$. thuringiensis var. kurstaki parsellerinde \%4.46, Thiodicarb'ta \%8.13 olarak belirlemişlerdir. Denemelerin ikinci kısmında ise bitki başına düşen larva sayısını $B$. thuringiensis var. kurstaki parselinde 0.12, Cryomazine'de 0.28, Diflubenzuron'da 0.34 ve CTPR+Abamectin'de 0.17 adet olarak belirlemişlerdir. Bulaşıklık oranını ise $B$. thuringiensis var. kurstaki parselinde \%15, Cryomazine'de \%24.42, Diflubenzuron'da \%25.97, CTPR+Abamectin'de ise \%4.94 olarak belirlemişlerdir. Elde ettikleri verilere göre araștırıcılar T. absoluta mücadelesinde CTPR+Abamectin'in en etkili ilaç olarak gözlendiğini, bundan sonra etkili olanın ise $B$. thuringiensis var. kurstaki olduğunu belirtmişlerdir. Bu çalışmada da literatürle bir benzerlik olduğu görülmektedir [38].

Dünyada yapılan çalışmalarda Chlorantraniliprole aktif maddesinin zararlı lepidopterlere karşı kökten verildiğinde iyi etki gösterdiği bildirilmiştir [31, 32, 33, 34, 35, 39]. Yapılan bir çalışmada bir sezon boyunca Ostrinia nubialis (Hubner)'in mücadelesinde dipten sulama yoluyla iki kez uygulanan chlorantraniliprole'in, yapraktan dokuz kez yapılan uygulama kadar etkili olduğunu belirtmişlerdir [34]. Son yıllarda yapılan çalışmalara bakıldı̆̆ında yapraktan yapılan chlorantraniliprole uygulamasının sistemik etkinliğinin, uygulama zamanında bitkinin boyuna ve hangi aşamada olduğuna bağlı olduğu bildirilmiștir [40]. Chlorantraniliprole aktif maddesi bitkilerde ksilem boyunca hareket eder ve onlar tarafından taşınmaktadır. $\mathrm{Bu}$ sayede topraktan verilen aktif maddenin bitkide yukarlara doğru taşındığı görülmekte ve zararlılara karşı etkili olduğu bilinmektedir [31]. Yapılan bir çalışmada soya fasulyesinde zarar yapan misır kurdunun ve diğer zararlı lepidopterlerin mücadelesinde chlorantraniliprole aktif maddesinin flubendiamide aktif maddesinden sistemik etki açısından daha üstün olduğunu belirtilmiştir [41].

Uygulama yapıldıktan sonraki toplam sayımlardan elde edilen sonuçlara göre topraktan uygulanan İlaç1 ve İlaç2 uygulamalarında canlı larva ve galeri sayılarının oldukça düșük, ölü larva sayılarının ise yüksek olduğu görülmektedir. Zararlının bu bitkileri tercih etmemesine bu kimyasalların topraktan uygulanmasının neden olduğu düşünülmektedir. Ancak İlaç1 isimli kimyasal, üreticilerin tercih ettiği gibi üstten püskürtme yöntemiyle uygulandığında, 
canlı larva ve galeri sayılarının üstteki iki uygulamaya göre yüksek olduğu görülürken; ölü larvaların sayılarının ise düşük olduğu tespit edilmiştir. Buna göre topraktan uygulanan kimyasalların daha etkili olduğu belirlenmiştir. İlaç3 isimli kimyasalın ise topraktan uygulanan diğer iki kimyasal kadar etkili olmadı̆̆ı, elde edilen verilerin üstten uygulaması yapılan İlaç1 isimli kimyasaldan elde edilen sonuçlara yakın olduğu saptanmıștır.

Elde edilen bütün sonuçlar karşılaştırıldığında İlaç1 ve İlaç2 isimli kimyasalların topraktan uygulandığında Tuta absoluta'ya karşı etkili olduğu söylenmektedir. Değişik bölgelerde domates üretimi yapan üreticilere de bu topraktan uygulama yönteminin başarılı olabilme potansiyelinin olduğu belirtilebilir. Ancak tarım ilaçlarının topraktan uygulanmasının zararlılara karşı direnç gelişimini hızlandırabilme riski olduğu göz ardı edilmemelidir. $\mathrm{Bu}$ nedenle söz konusu yöntemler üzerine arazi koşullarında ve uygulamadan sonra meyve analizleri konusunda daha gelişmiş çalışmalar yapılmasında fayda olacağı düşünülmektedir.

\section{Kaynakça}

[1] Karabüyük, F. 2011. Doğu Akdeniz Bölgesi Sebze Alanlarında Domates Yaprak Galeri Güvesi Tuta absoluta (Meyrick, 1917)'nın Popülasyon Gelişmesi, Yayılıșı, Konukçuları ile Parazitoit ve Predatörlerinin Saptanması. Çukurova Üniversitesi Fen Bilimleri Enstitüsü, Yüksek Lisans Tezi, 48s, Adana.

[2] Anonim, 2011. Domates Hastalık ve Zararlıları ile Mücadele. Gıda Tarım ve Hayvancılık Bakanlığı, Koruma ve Kontrol Genel Müdürlüğü Bitki Sağlığı ve Karantina Daire Başkanlığı, 68 s, Ankara.

[3] Anonim, 2016. Tomatoes production on the World.http://www.fao.org/faostat/en/\#data/Q C (Erişim Tarihi: 03.07.2018).

[4] Anonim, 2017. Türkiye'de domates üretimi. http://www.tuik.gov.tr/PreTablo.do?alt_id=100. (Erişim Tarihi: 03.07.2018).

[5] TUIK, 2014. Bitkisel Üretim İstatistikleri. http://tuik.gov.tr/PreTablo.do?alt_id=1001 (Erişim tarihi: 4.2.2015).

[6] Anonim, 2005. European and Mediterranean Plant Protection Organization data sheets on quarantine pests. OEPP/EPPO Bulletin, 35, 434435.

[7] Kılıç, T. 2010. First record of Tuta absoluta in Turkey. Phytoparasitica, 38(3), 243-244.

[8] Harizanova, V., Stoeva, A., Mohamedova, M. 2009. Tomato leaf miner, Tuta absoluta (Meyrick, 1917) (Lepidoptera: Gelechiidae) first record in Bulgaria. Agricultural Science and Technology, 1(3), 95-98.
[9] Roditakis, E., Papachristos, D., Roditakis, N. E. 2010. Current status of the tomato leafminer Tuta absoluta in Greece. Bulletin OEPP/EPPO Bulletin, 40, 163-166.

[10] Bloem, S., Spaltenstein, E. 2011. New Pest Response Guidelines Tomato Leafminer (Tuta absoluta). Emergency and Domestic Programs, United States , 176p.

[11] Karut, K., Kazak, C., Döker, İ., Ulusoy, M.R. 2011. Mersin ili domates seralarında domates yaprak galeri güvesi Tuta absoluta (Meyrick, 1917) (Lepidoptera: Gelechiidae)'nın yaygınlığı ve zarar durumu. Türkiye Entomoloji Dergisi, 35(2), 339-347.

[12] Loni, A., Rossi, E., van Achterberg, K. 2011. First report of Agathis fuscipennis in Europe as parasitoid of the tomato leafminer Tuta absoluta. Bulletin of Insectology, 64(1), 115-117.

[13] Tatlı, E., Göçmen, H. 2011. Domates güvesi, Tuta absoluta (Meyrick, 1917) (Lepidoptera: Gelechiidae)'nın Batı Akdeniz Bölgesi domates üretim alanlarında yayılışının ve popülasyon değişiminin izlenmesi. Türkiye IV. Bitki Koruma Kongresi, 28-30 Haziran 2011, Kahramanmaraş, 271.

[14] Ünlü, L. 2012. Potato: A new host plant of Tuta absoluta Povolny (Lepidoptera: Gelechiidae) Turkey. Pakistan Journal of Zoology, 44(4), 1183-1184.

[15] Balzan, M. V., Moonen, A. C. 2012. Management strategies for the control of Tuta absoluta (Lepidoptera: Gelechiidae) damage in open-field cultivations of processing tomato in Tuscany (Italy). Bulletin OEPP/EPPO Bulletin, 42(2), 217225.

[16] Öztemiz, S. 2012. Domates güvesi Tuta absoluta Meyrick (Lepidoptera: Gelechiidae) ve biyolojik mücadelesi. Kahramanmaraş Sütçü İmam Üniversitesi, Doğa Bilimleri Dergisi, 15(4), 4757.

[17] Cuthbertson, A. G. S., Mathers, J. J., Blackburn, L. F., Korycinska, A., Luo, W., Jacobson, R. J., Northing, P. 2013. Population development of Tuta absoluta (Meyrick) (Lepidoptera: Gelechiidae) under simulated UK glasshouse conditions. Insects, 4, 185-197.

[18] Portakaldalı, M., Öztemiz, S., Kütük, H., Büyüköztürk, H. D., Çolak Ateş, A. 2013. Doğu Akdeniz ve Güneydoğu Anadolu Bölgeleri'nde Tuta absoluta (Meyrick, 1917) (Lepidoptera: Gelechiidae)'nın yayılış durumu. Türkiye Entomoloji Bülteni, 3(3), 133-139.

[19] Bayram, Y., Bektaş, Ö., Büyük, M., Bayram, N., Duman, M., Mutlu, Ç. 2014. Güneydoğu Anadolu Bölgesi'nde domates güvesi [(Tuta absoluta Meyrick) (Lepidoptera: Gelechiidae)] ve doğal 
düşmanlarının sürveyi. Türkiye Biyolojik Mücadele Dergisi, 5(2), 99-110.

[20] Arnó, J., Gabarra, R. 2010. Controlling Tuta absoluta, a new invasive pest in Europe. Training in Integrated Pest Management-Number 5, Project number: 031499.

[21] Ögür, E., Ünlü, L., Karaca, M. 2014. Chenopodium album L.: A new host plant of Tuta absoluta Povolny (Lepidoptera: Gelechiidae). Türkiye Entomoloji Bülteni, 4(1), 61-65.

[22] Seplyarsky V., Moshe W., Ami H. 2010. Tuta absoluta Povolny (Lepidoptera: Gelechiidae), a new invasive species in Israel. Phytoparasitica, 38(5), 445-446.

[23] Sparks, T. C. 1981. Development of insecticide resistance in Heliothis zea and Heliothis virescens in North America. Bulletin of the Entomological Society of America, 27, 186-192.

[24] Brown, T. M., Bryson, P. K., Brickle, D. D., Pimprale, S., Arnette, F., Roof, M. E., Walker, J. T., Sullivan, M. J. 1998. Pyrethroid-resistant Helicoverpa zea and transgenic cotton in South Carolina. Crop Protection, 17, 441-445.

[25] Temple, J. H., Cook, D. R., Bommireddy, P. L., Micinski, S., Waltman, W., Stewart, A. M., Garber, B., Leonard, B. R. 2006. Monitoring cypermethrinsusceptibility in Louisiana bollworm 2004-2005, pp. 1236-1240. In Proceeding Beltwide Cotton Conference, 3-6 January 2006, San Antonio, TX. National Cotton Council America, Memphis, TN.

[26] Jacobson, A., Foster, R., Krupke, C., Hutchison, W., Pittendrigh, B., Weinzierl, R. 2009. Resistance to pyrethroids insecticides in Helicoverpa zea (Lepidoptera: Noctuidae) in Indiana and Illinois. Journal of Economical Entomology, 102, 22892295.

[27] Lai, T., Su, J. 2011. Assessment of resistance risk in Spodoptera exigua (Hubner) (Lepidoptera: Noctuidae) to chlorantraniliprole. Pest Management Science, 67, 1468-1472.

[28] Environmental Protection Agency (EPA), 2008. Pesticide fact sheet, Chlorantraniliprole.http://www3.epa.gov/pesti cides/chem_search/reg_actions/registration/fs_ PC-090100_01-Apr-08.pdf) (Erişim Tarihi: 01.01. 2016).

[29] Insecticide Resistance Action Committee (IRAC), 2015. IRAC mode of action classification scheme. Version 8.0 [Online]. (http://www.iraconline.org/documents/moa-classification/) (Erişim Tarihi: 01.01. 2016).

[30] Lahm, G. P., Cordova, D., Barry, J. D. 2009. New and selective ryanodine receptor activators for insect control. Bioorganic and Medicinal Chemistry, 17, 4127-4133.
[31] Lahm, G. P., Stevenson, T. M., Selby, T. P., Freudenberger, J. H., Cordova, D., Flexner, L., Bellin, C. A., Dubas, C. M., Smith, B. K., Hughes, K. A. 2007. Rynaxypyr: a new insecticidal anthranilic diamide that acts as a potent and selective ryanodine receptor activator. Bioorganic and Medicinal Chemistry Letter, 17, 6274-6279.

[32] Kuhar, T. P., Doughty, H., Hitchner, E., Cassell, M. 2008. Evaluation of insecticide treatments for the control of lepidopteran pests in bell peppers in Virginia, 2007. Arthropod Management Tests, 33, E7.

[33] Palumbo, J. C. 2008. Systemic efficacy of Coragen applied through drip irrigation on romaine lettuce, fall 2007. Arthropod Management Tests, 33, E24.

[34] Ghidiu, G. M., Ward, D. L., Rogers, G. S. 2009. Control of European corn borer in bell peppers with chlorantraniliprole applied through a drip irrigation system. International Journal of Vegetable Science, 15, 193-201.

[35] Schuster, D. J., Shurtleff, A., Kalb, S. 2009. Management of armyworms and leafminers on fresh market tomatoes, fall 2007. Arthropod Management Tests, 34, E79.

[36] Cameron, R. A., Williams, C. J., Portillo, H. E., Marcon, P. C., Teixeira, L. A. 2015. Systemic application of chlorantraniliprole to cabbage transplants for control of foliar-feeding lepidopteran pests. Crop Protection, 67, 13-19.

[37] Hardke, J. T., Temple, J. H., Leonard, B. R., Jackson, R. E. 2011. Laboratory toxicity and field efficacy of selected insecticides against fall armyworm (Lepidoptera: Noctuidae). Florida Entomologist, 94, 272-278.

[38] Doğanlar, M., Yıldırım, A. E., Yiğit, A. 2011. Sera domateslerinde zararlı Tuta absoluta (Meyrick) (Lepidoptera: Gelechiidae) mücadelesinde çevre dostu bazı ilaçların etkileri. Türkiye IV. Bitki Koruma Kongresi, 28-30 Haziran 2011, Kahramanmaraș, 54.

[39] Ghidiu, G. M., Kuhar, T., Palumbo, J., Schuster, D. 2012. Drip chemigation of insecticides as a pest management tool in vegetable production. Journal of Integrated Pest Management, 3, E1E5.

[40] Pedersen, P. 2004. Soybean growth and development. Iowa State University, Ames, IA. PM1945.

[41] Adams, A., Gore, J., Catchot, A., Musser, F., Cook, D., Krishnan, N., Irby, T. 2016. Residual and Systemic Efficacy Chlorantraniliprole and Flubendiamide Against Corn Earworm (Lepidoptera: Noctuidae) in Soybean. Journal of Economic Entomology, 109(6), 2411-2417. 